\title{
Chronic Kidney Disease with Pregnancy: Hemodialysis can be considered for Better Maternal and Fetal Outcomes
}

\author{
Sumesh Choudhary ${ }^{1}$, Vineet V Mishra ${ }^{2}$, Saiprasad Shinde ${ }^{3}$, Himanshu Patel ${ }^{4}$, Rohina Aggarwal ${ }^{5}$, Khushali Gandhi ${ }^{6}$
}

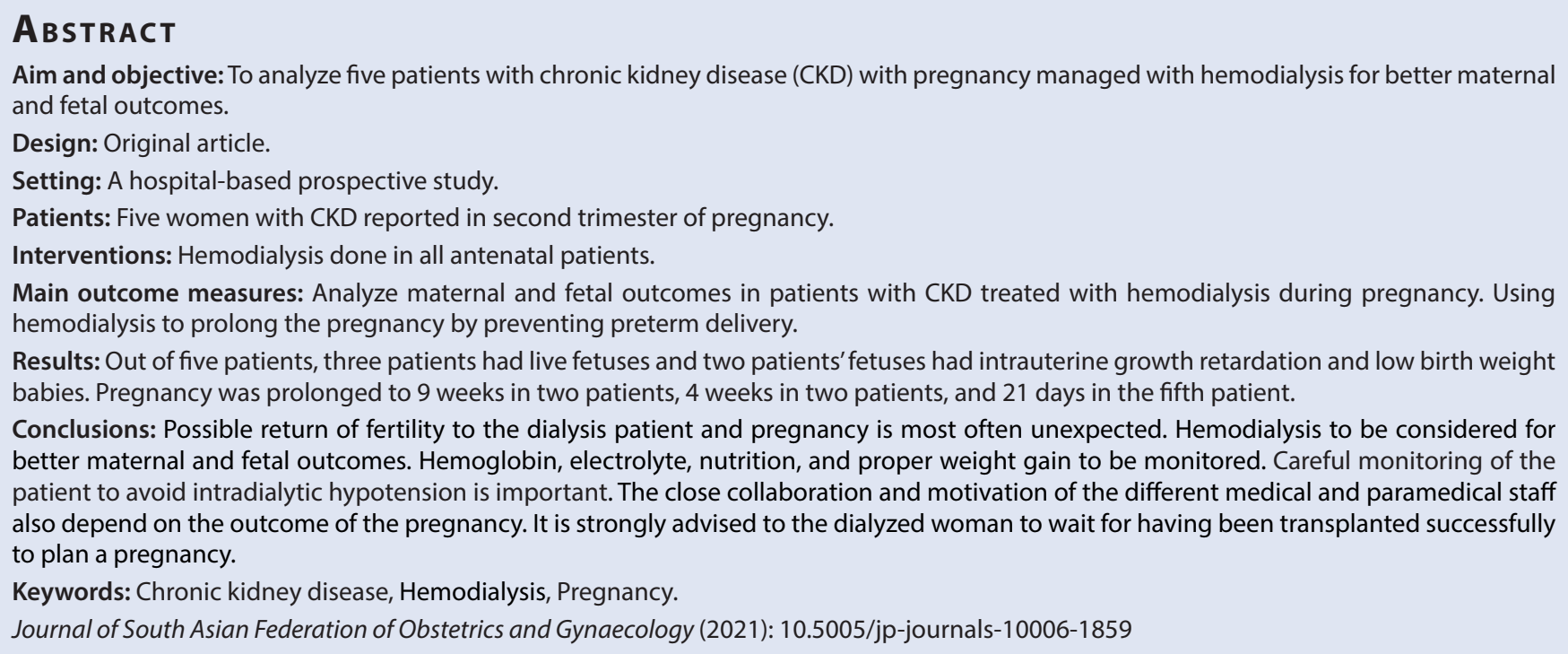

\section{INTRODUCTION}

Chronic kidney disease (CKD) is a nonspecific term that does not indicate the cause of kidney disease but it is useful for improving communications with investigators, practitioners, and the public. CKD is defined as kidney injury and/or impaired kidney function lasting three or more months. Recent guidelines stage CKD according to levels of kidney function irrespective of the type of kidney disease. ${ }^{1}$ Pregnancy in women with CKD is considered high risk. Diseased kidneys may be unable to adapt to the normal physiologic changes of pregnancy leading to perinatal complications. ${ }^{2}$ Pregnancy is associated with variable effects on pre-existing kidney disease. Proteinuria increases in about $50 \%$ of cases and hypertension develops in about $25 \%$ of cases The conception rate among women of reproductive age on dialysis is about $0.3-1.5 \%$ per year. ${ }^{3}$ Severe hypertension can cause maternal and fetal complications. ${ }^{4}$ These changes usually resolve after delivery. Pregnancy is associated with permanent deterioration of renal function in nearly $10 \%$ of cases when there is only mild baseline renal dysfunction (serum creatinine $<1.5 \mathrm{mg} / \mathrm{dL}$ ). ${ }^{5}$ The patients reporting in second and third trimesters of pregnancy with CKD are a challenge for obstetricians and nephrologists. The decision is to be taken whether to continue the pregnancy, abort the pregnancy, or continue the pregnancy on dialysis. The objective of this work is to report our experience regarding the continuation of pregnancy in CKD patients with dialysis.

\begin{abstract}
1,2,5,6 Department of Obstetrics and Gynecology, Institute of Kidney Disease and Research Centre-Institute of Transplantation Sciences, Ahmedabad, Gujarat, India

${ }^{3,4}$ Department of Nephrology, Institute of Kidney Disease and Research Centre, Ahmedabad, Gujarat, India

Corresponding Author: Sumesh Choudhary, Department of Obstetrics and Gynecology, Institute of Kidney Disease and Research Centre-Institute of Transplantation Sciences, Ahmedabad, Gujarat, India, e-mail: drsumeshchoudhary@gmail.com

How to cite this article: Choudhary S, Mishra VV, Shinde S, et al. Chronic Kidney Disease with Pregnancy: Hemodialysis can be considered for Better Maternal and Fetal Outcomes. J South Asian Feder Obst Gynae 2021;13(1):11-14.
\end{abstract}

Source of support: Nil

Conflict of interest: None

\section{Materials and Methods}

From July 2016 to April 2017, five women with CKD and pregnancy reported at the Obstetrics and Gynecology unit of the Institute of Kidney Disease and Research Centre-Institute of Transplantation Sciences (IKDRC-ITS), Ahmedabad. Patients were advised not to conceive due to renal function status, but they conceived and reported in the late second trimester of pregnancy. Due to pregnancy, their condition deteriorated when reported to the hospital. Dialysis was started as part of treatment to compensate the renal function. These patients were followed up to 6 weeks postdelivery.

(c) Jaypee Brothers Medical Publishers. 2021 Open Access This article is distributed under the terms of the Creative Commons Attribution 4.0 International License (https://creativecommons.org/licenses/by-nc/4.0/), which permits unrestricted use, distribution, and non-commercial reproduction in any medium, provided you give appropriate credit to the original author(s) and the source, provide a link to the Creative Commons license, and indicate if changes were made. The Creative Commons Public Domain Dedication waiver (http://creativecommons.org/publicdomain/zero/1.0/) applies to the data made available in this article, unless otherwise stated. 


\section{Case Descriptions}

Case 1: A 37-year-old patient, with a diagnosed case of CKD, was transferred to our hospital with oliguria, swelling all over the body, and amenorrhea of 28 weeks. On examination, the general condition was poor; with pallor and edema all over the body, blood pressure was $170 / 110 \mathrm{~mm} \mathrm{Hg}$. The investigation revealed the following: $\mathrm{Hb}-7.1 \mathrm{~g} / \mathrm{dL}, \mathrm{PCV}-21.6 \%$, serum creatinine $-4.38 \mathrm{mg} /$ $\mathrm{dL}$, serum urea-110 mg/dL, serum electrolyte $\mathrm{Na}^{+}-129.43 \mathrm{mEq} / \mathrm{L}$, $\mathrm{K}^{+}-4.5 \mathrm{mEq} / \mathrm{L}$, and urine protein $-500 \mathrm{mg} / \mathrm{dL}$. Fetal ultrasound revealed a fetus of 26 weeks period of gestation with weight $700 \mathrm{~g}$ and liquor moderate quantity. With discussion and concurrence with the nephrologist, the patient was put on hemodialysis. The patient's condition improved, and dialysis was done on alternate days. Serum creatinine was maintained between $4 \mathrm{mg} / \mathrm{dL}$ and $6 \mathrm{mg} / \mathrm{dL}$. Serum urea was maintained below $45 \mathrm{mg} / \mathrm{dL}$. Electrolyte and bicarbonates were maintained at an optimal level. Hemoglobin 8-9 g/dL was maintained by blood transfusion. Postdialysis fetal Doppler was done for the fetal heart. The patient condition improved, and pregnancy was continued for 4 weeks. During treatment, an arteriovenous fistula was created. But after 4 weeks, the fetus started showing Oligohydraminos and reversal in umbilical flow. As the patient had a previous cesarean, an elective cesarean was planned. Preoperative dialysis was done and a female baby of $1000 \mathrm{~g}$ was delivered. The newborn expired after 15 days due to sepsis.

Case 2: A 22-year-old patient, a diagnosed case of CKD, with dysfunctional bladder reported with 28 weeks of pregnancy. On examination, the general condition was poor, and blood pressure was $170 / 100 \mathrm{~mm} \mathrm{Hg}$. The investigation revealed the following: serum creatinine- $5.53 \mathrm{mg} / \mathrm{dL}$, serum urea- $67 \mathrm{mg} /$ $\mathrm{dL}$, serum electrolyte $\mathrm{Na}^{+}-140.1 \mathrm{mEq} / \mathrm{L}, \mathrm{K}^{+}-4.9 \mathrm{mEq} / \mathrm{L}$, and urine protein $-150 \mathrm{mg} / \mathrm{dL}$; microscopy showed pus cells and 10 to 20 red blood cells. Ultrasound showed a fetus of $800 \mathrm{~g}$ with mild oligohydramnios and bilateral contracted kidney of the patient. After discussion with the nephrologist, the patient was put on dialysis. Her condition improved with dialysis. Arteriovenous fistula was created. The fetal condition was regularly monitored with ultrasound and umbilical Doppler. After 30 days of treatment, ultrasound showed oligohydramnios with altered Doppler and fetal weight of $1.2 \mathrm{~kg}$. Fetus delivered by cesarean. Due to preterm and fetal distress. Post operatively patient recovered well but the fetus died after 25 days due to sepsis.

Case 3: A 23-year-old patient, a diagnosed case of CKD, reported with 28 weeks of pregnancy. On examination, the general condition was good and blood pressure 170/100 mm Hg. The investigation revealed the following: serum creatinine $-7.5 \mathrm{mg} /$ $\mathrm{dL}$, serum urea- $90 \mathrm{mg} / \mathrm{dL}$, serum electrolyte- $\mathrm{Na}^{+}-140.1 \mathrm{mEq} / \mathrm{L}$, $\mathrm{K}^{+}-4.8 \mathrm{mEq} / \mathrm{L}$, and urine protein $-500 \mathrm{mg} / \mathrm{dL}$; microscopy showed 6-8 pus cells and $10-20$ red blood cells. Ultrasound showed a fetus of $1200 \mathrm{~g}$ with normal liquor, and the patient had bilateral contracted kidney. After discussion with the nephrologist, the patient was put on dialysis. Her condition improved with dialysis. Arteriovenous fistula was created. Hemoglobin was maintained with blood transfusion during dialysis. Urea was maintained below $45 \mathrm{mg} / \mathrm{dL}$. Regular fetal ultrasound was done, and the patient was admitted for 60 days. When fetal weight was $2.2 \mathrm{~kg}$, it was delivered by cesarean. The mother and fetus were followed for 45 days, and they both were healthy. Mother was counseled to conceive after renal transplantation.

Case 4: A 20-year-old patient, a diagnosed case of CKD, reported with 30 weeks of pregnancy. On examination, the general condition was good and blood pressure $160 / 100 \mathrm{~mm} \mathrm{Hg}$. The investigation revealed the following: serum creatinine- $2.3 \mathrm{mg} /$ $\mathrm{dL}$, serum urea $-75 \mathrm{mg} / \mathrm{dL}$, serum electrolyte $\mathrm{Na}^{+}-140.1 \mathrm{mEq} / \mathrm{L}$; $\mathrm{K}^{+}-4.8 \mathrm{mEq} / \mathrm{L}$, and urine protein $-500 \mathrm{mg} / \mathrm{dL}$; microscopy showed pus cells and 10-20 red blood cells. Ultrasound showed a fetus of $1100 \mathrm{~g}$ with liquor normal. Patient ultrasound showed mild hydronephrosis in both kidneys with loss of corticomedullary differentiation. The patient was a known case of CKD, on antihypertensive telmisartan and sobisis since 2014. During that period, she had missed an abortion. In her first trimester, she was advised for medical termination of pregnancy but the patient refused and reported at 30 weeks. After discussion with the nephrologist, the patient was put on dialysis. The patient's condition improved with dialysis. Hemoglobin was maintained with blood transfusion during dialysis. Urea was maintained below $45 \mathrm{mg} / \mathrm{dL}$. The fetus was monitored with ultrasound and Doppler. After 3 weeks, ultrasound showed fetal weight of $1.4 \mathrm{~kg}$ with oligohydramnios and Absent diastolic flow in umbilical artery waveform Doppler. Delivery was planned by cesarean. The fetus of $1.4 \mathrm{~kg}$ was sent to neonatal intensive care. Mother and fetus were followed for a month; they both were healthy. Mother was counseled to conceive after renal transplantation.

Case 5: A 30-year-old second gravida presented to the obstetrics department for management of 5-month twin pregnancy with fever. She had one previous abortion at 3 months amenorrhea. No significant medical or surgical history. On examination, the patient was averagely built and poorly nourished. Pallor present, with no edema. Blood pressure, $130 / 80 \mathrm{~mm}$ and $\mathrm{Hg}$ pulse, $100 \mathrm{~min}$. The investigation revealed the following: $\mathrm{Hb}-4.9 \mathrm{~g} /$ $\mathrm{dL}$, serum creatinine- $6.6 \mathrm{mg} / \mathrm{dL}$, and serum urea-100 mg/dL; ultrasound suggested bilateral shrunken kidneys with loss of corticomedullary pattern, and intrauterine twin pregnancy of 25 weeks maturity with fetal weight of $600 \mathrm{mg}$. The patient was evaluated for elevated creatinine. Markers for the autoimmune disease were negative. After consultation with the nephrologist, the patient was put on maintenance hemodialysis three times a week. Her serum creatinine throughout the pregnancy remained above $4 \mathrm{mg} / \mathrm{dL}$ and blood urea, $50 \mathrm{mg} / \mathrm{dL}$. She never had albuminuria and hypertension. A total of five packed red blood cells were transfused with dialysis to correct anemia. Fetal monitoring was done after dialysis with ultrasound and Doppler. Serial fetal ultrasound suggested weight gain in both fetuses, but there was discordant growth. Smaller Twin had altered Doppler in form of raised umbilical SD ratio and normal middle cerebral artery Doppler but the liquor was present in normal range of the amniotic fluid index. The pregnancy was continued up to 34 weeks of gestation and delivered the patient by LSCS under spinal anesthesia because of severe intrauterine growth retardation in both twin pregnancies. One baby was $1.6 \mathrm{~kg}$ and the second was $0.955 \mathrm{~kg}$. Both babies were admitted to the neonatal care unit for the management of preterm and low birth weight. The postpartum period was uneventful and she was put on maintenance hemodialysis twice a week.

\section{Results}

The Study group's age was between 20 years and 37 years, and they all reported between 25 weeks and 30 weeks period of gestation. Serum creatinine was in the range of $2.5-7.5 \mathrm{mg} / \mathrm{dL}$, and blood urea was 80 to $110 \mathrm{mg} / \mathrm{dL}$ (Table 1). Fetal weight gain with dialysis was between $400 \mathrm{~g}$ and $1200 \mathrm{~g}$. Pregnancy was prolonged up to 4- 
Hemodialysis with CKD in Pregnancy

\begin{tabular}{|c|c|c|c|c|c|c|c|c|c|}
\hline Serial no. & Age & $\begin{array}{l}\text { Reported at } \\
\text { (POG) (weeks) }\end{array}$ & $\begin{array}{l}\text { Serum creati- } \\
\text { nine }\end{array}$ & $H b$ & Urea & $\begin{array}{l}\text { Fetal wt. (ultra- } \\
\text { sonography) (g) }\end{array}$ & $\begin{array}{l}\text { Days of } \\
\text { admission (days) }\end{array}$ & Delivered (weeks) & $\begin{array}{l}\text { Fetal weight } \\
\text { (g) }\end{array}$ \\
\hline 1 & 37 & 28 & 4.38 & 7 & 110 & 600 & 30 & 32 & 1000 \\
\hline 2 & 22 & 28 & 5.53 & 8 & 87 & 800 & 32 & 32 & 1200 \\
\hline 3 & 23 & 28 & 7.5 & 7.5 & 80 & 1200 & 60 & 36 & 2400 \\
\hline 4 & 20 & 30 & 2.3 & 7.5 & 90 & 1100 & 21 & 33 & 1400 \\
\hline 5 & 30 & 19 (twin) & 4.6 & 4.5 & 100 & 500 & 100 & 34 & $\begin{array}{r}1600 \\
995\end{array}$ \\
\hline
\end{tabular}

Table 2: Fetal outcome with CKD and pregnancy treated with hemodialysis

\begin{tabular}{|c|c|c|c|c|}
\hline $\begin{array}{l}\text { Serial } \\
\text { no. }\end{array}$ & $\begin{array}{l}\text { Fetal } \\
\text { weight } \\
\text { gain }(g)\end{array}$ & $\begin{array}{l}\text { Intrauterine } \\
\text { complica- } \\
\text { tions }\end{array}$ & $\begin{array}{l}\text { NICU admis- } \\
\text { sion }\end{array}$ & Fetal outcome \\
\hline 1 & 400 & IUGR & Yes & Died due to sepsis \\
\hline 2 & 400 & IUGR & Yes & Died due sepsis \\
\hline 3 & 1200 & NIL & No & Alive and healthy \\
\hline 4 & 300 & IUGR & Yes & $\begin{array}{l}\text { Alive and gaining } \\
\text { weight }\end{array}$ \\
\hline 5 & $\begin{array}{r}1100 \\
500\end{array}$ & IUGR & Yes & $\begin{array}{l}\text { Alive and gaining } \\
\text { weight }\end{array}$ \\
\hline
\end{tabular}

9 weeks (Table 2). The fetal outcome showed one term fetus and three preterm with intrauterine growth retardation. Hemodialysis was done at least four times in a week in all patients. All patients' hemoglobin was maintained between $8 \mathrm{~g} / \mathrm{dL}$ and $9 \mathrm{~g} / \mathrm{dL}$ with blood transfusion during dialysis. Urea was maintained below $45 \mathrm{mg} / \mathrm{dL}$ with dialysis. The average time of dialysis was 8 hours.

\section{Discussion}

The occurrence of Pregnancy in chronic Haemodyialasis is rare, and their development is precarious, but since Confortini described the first case in 1971, several observations have been reported. ${ }^{6}$ These pregnancies constitute a high-risk group and lead to living neonates only in $60 \%$ of the cases, because of fetal complications. ${ }^{7}$ The current survey in Japan revealed that the rate of successful pregnancy in women on dialysis has improved. More than half of the pregnancies resulted in infant survival. But premature birth is a major problem for the children of women on dialysis, and there is a higher rate of neonatal death. ${ }^{8}$

When the pregnancy is known, the role of the nephrologist is to adapt the hemodialysis protocol, to ensure good control of blood pressure, dry weight, hemoglobin, and nutritional intakes. The frequency of hemodialysis should be increased as soon as possible to four sessions and then to six sessions per week from the fifth month to optimize metabolic control and volemia with a goal of 16 to 24 hours of hemodialysis weekly, which is found associated with a better fetal prognosis. ${ }^{9}$ A modification of the parameters of dialysis is carried out by many nephrological teams. Blood urea nitrogen should be maintained below $45 \mathrm{mg} \%$, which is achieved by increasing dialysis frequency. ${ }^{10}$ Bicarbonates, increasing potassium, and blood urea should be monitored. The flow rates of the blood pump are 200 to $250 \mathrm{~mL} / \mathrm{min}$, which is good for the pregnant patient. Fatigue should be avoided as much as possible during sessions that are highly detrimental to the fetus and should monitor frequent uterine contractions at the end of sessions in the second and third trimester of pregnancy. Good control of blood pressure requires a fair evaluation of the dry weight, an estimate that remains mainly clinical, aided by knowledge of the "ideal" physiological weight gain during pregnancy, which is 1 to $1.5 \mathrm{~kg}$ in the first trimester and then $500 \mathrm{~g} /$ week in the second and third trimesters. ${ }^{11}$ The goal of hemoglobin in healthy pregnant women is 9-11.5 g/dL. ${ }^{12}$ Transfusion should be avoided as a source of alloimmunization, especially in pregnant women. ${ }^{13}$ There are no erythropoietin receptors in the human placenta or secondary complications related to the use of erythropoietin during pregnancy. The use or early increase in erythropoietin dosage reduces the frequency of transfusion by 77 to $26 \% .{ }^{14} \mathrm{~A}$ problem specific to women in hemodialysis is the development of thrombosis of their arteriovenous fistulas, preventing vascular access. Despite a more intensive renal dialysis regimen and an increase in prenatal surveillance, these pregnancies remain at very high risk. The collaboration of the nephrologist with the obstetricians must be continuous with clinical and ultrasound monitoring from the second trimester in search of hydramnios and fetal development. In almost all situations, the decision of cesarean section is made urgently due to the occurrence of a maternal or fetal complication. Delivery, when it is anticipated, leads to further intensification of dialysis within 48 hours. The goal is for the baby to be born with the lowest uremia and creatinine levels possible, in order to limit osmotic complications at birth. The cases we reported lead us to believe that there is also a place for pregnancy in patients with CKD with hemodialysis. Although this dialysis in pregnancy is technically possible, it is also strongly discouraged, ideally being able to wait until the renal transplantation, when the latter is possible. ${ }^{15}$

\section{Conclusion}

Possible return of fertility to the dialysis patient and pregnancy is most often unexpected due to ignorance. Her diagnosis is often delayed, and her technical care becomes challenging for the multidisciplinary team that follows her. Hemoglobin level should be kept at about 10-11 g/dL. Correction of hypocalcemia and metabolic acidosis is necessary. Careful monitoring of the patient to avoid intradialytic hypotension is important. Attention should be given to nutritional considerations and proper weight gain. In addition, pregnancy and blood transfusion may cause maternal alloimmunization that is detrimental to a future renal transplant. The close collaboration and motivation of the different medical and paramedical staff also depend on the outcome of the pregnancy. It is strongly advised to the CKD woman to wait for having been transplanted successfully to plan a pregnancy. 


\section{References}

1. National Kidney Foundation. K/DOQI clinical practice guidelines for chronic kidney disease: evaluation, classification, and stratification. Am J Kidney Dis 2002;39:S1-S266.

2. Fischer MJ, Lehnerz SD, Hebert JR, et al. Kidney disease is an independent risk factor for adverse fetal and maternal outcomes in pregnancy. Am J Kidney Dis 2004;43:415-423. DOI: 10.1053/j. ajkd.2003.10.041.

3. Hou S. Pregnancy in chronic renal insufficiency and end-stage renal disease. Am J Kidney Dis 1999;33:235. DOI: 10.1016/s02726386(99)70296-9.

4. Hayslett JP. Interaction of renal disease and pregnancy. Kidney Int 1984;25:579. DOI: 10.1038/ki.1984.58.

5. Hou S. Pregnancy in women with chronic renal disease. N Engl J Med 1985;312:836. DOI: 10.1056/NEJM198503283121306.

6. Confortini P, Galanti G, Ancona G, et al. Full term pregnancy and successful delivery in a patient on chronic haemodialysis. Proc Eur Dial Transplant Assoc 1970;8:74-80.

7. Fischer MJ.Chronic kidney disease and pregnancy: maternal and fetal outcomes. Adv Chronic Kidney Dis 2007;14:132-145. DOI: 10.1053/j. ackd.2007.01.004.

8. Toma H, Tanabe K, Tokumoto T, et al. Pregnancy in women receiving renal dialysis or transplantation in Japan: a nationwide survey. Nephrol Dial Transplant 1999;14(6):1511-1516. DOI: 10.1093/ $n d t / 14.6 .1511$.

9. Hou S. Modification of dialysis regimens for pregnancy. Int J Artif Organs 2002;25(9):823-826. DOI: 10.1177/039139880202500902.

10. Asamiya $Y$, Otsubo S, Matsuda $Y$, et al. The importance of low blood urea nitrogen levels in pregnant patients undergoing hemodialysis to optimize birth weight and gestational age. Kidney Int 2009;75:1217. DOI: 10.1038/ki.2009.48.

11. Giatras I, Delphine P, Malone D. Pregnancy during dialysis: case report and management guidelines. Nephrol Dial Transplant 1998;13:32663272. DOI: 10.1093/ndt/13.12.3266.

12. Shemin D. Dialysis in pregnant women with chronic kidney disease. Sem Dial 2003;16(5):379-383. DOI: 10.1046/j.1525139x.2003.16084_1.x.

13. Sonfilippo F, Vaughn WK, Bollinger RR, et al. Comparative effects of pregnancy, transfusion, and prior graft rejection on sensitization and renal transplant results. Transplantation 1982;34(6):360-366. DOI: 10.1097/00007890-198212000-00010.

14. Pekonen $F$, Rosenlof $K$, Rutanean EM, et al. Erythropoietin binding sites in human fetal tissues. Acta Endocrinol 1987;116:561-567. DOI: 10.1530/acta.0.1160561.

15. Okundaye I, Abrinko P, Hou S. Registry of pregnancy in dialysis patients. Am J Kidney Dis 1998;31(5):766-773. DOI: 10.1016/s02726386(98)70044-7. 